\title{
A placebo controlled, crossover study of azathioprine in Reiter's syndrome
}

\author{
ANDREI CALIN \\ From the Royal National Hospital for Rheumatic Diseases, Bath
}

SUMMARY Eight patients with intractable Reiter's disease were entered into a double blind, placebo controlled, crossover study of azathioprine versus placebo-each patient serving as his own control. Drug therapy was administered for 16 weeks, patients receiving azathioprine (eight weeks) or placebo (eight weeks) in random order. Azathioprine was given as $1 \mathrm{mg} / \mathrm{kg}$ body weight for the first month and $2 \mathrm{mg} / \mathrm{kg}$ body weight for the second month. Six individuals completed both arms of the crossover. One withdrew because 'of nausea during the first week (azathioprine), and a second subject withdrew at four weeks because of lack of efficacy (placebo). At the end of the 16 weeks five out of six preferred azathioprine and one placebo. The mean unweighted joint score decreased from 19.8 to 2.7 during the azathioprine medication but increased from 13.4 to 19.9 during the placebo period. Patients were unable to reduce their analgesic or non-steroidal anti-inflammatory drug requirements during the placebo period, but four out of six were able to do so during azathioprine therapy. There were no drug related laboratory abnormalities. The data suggest that azathioprine may work rapidly in Reiter's disease. If these essentially anecdotal findings of efficacy are confirmed, long term toxicity may not be an over-riding factor since for some patients therapy can be rapidly tapered at eight weeks-either because of adequate improvement or failure to respond.

Reiter's syndrome is frequently a chronic disease. ${ }^{1}$ Treatment may present a major problem both for patient and physician alike. One major text fails to mention corticosteroids, gold, or penicillamine. ${ }^{2}$ Presumably such drugs are considered controversial or inefficacious. The varied course results in frustration for both patient and physician. ${ }^{3}$ Antibiotic therapy may be considered inappropriate ${ }^{4}$ or controversial, support only coming from one uncontrolled study with Lincomycin. ${ }^{5}$ For those individuals with relentlessly progressive disease a trial of cytotoxic therapy may be used as suggested by the effect of methotrexate in psoriatic arthropathy. ${ }^{6}$ Uncontrolled data suggest that methotrexate may be suitable. $^{78}$

Our anecdotal experience suggested that low to medium dose azathioprine may be helpful, and we were impressed that improvement occurred rapidly within four to eight weeks. For this reason we

Accepted for publication 4 February 1986.

Correspondence to Dr A Calin, Royal National Hospital for Rheumatic Diseases, Upper Borough Walls, Bath BA1 1RL. attempted a double blind, controlled study. As one would expect the logistics of such an investigation were extremely complicated. In view of the difficulty of studying a sufficient number of patients with comparable disease a smaller, double blind study was performed, each individual acting as his or her own control.

Herein we report our experience of eight such patients. Individuals received either azathioprine or placebo for eight weeks followed by the alternative agent.

\section{Patients and methods}

Eight patients (six male, two female) with intractable Reiter's disease were admitted to the study. Reiter's syndrome was defined as a seronegative, asymmetric arthropathy with predominantly lower extremity involvement. ${ }^{4}$ All individuals had, in addition to the arthropathy, urethritis plus inflammatory eye disease or mucocutaneous involvement such as balanitis, oral ulceration, or keratoderma blennorrhagicum. Sacroiliitis occurred in two patients, and six had systemic complaints. Patients 
with psoriatic arthropathy, primary ankylosing spondylitis, or other rheumatic diseases were excluded. The age range was $27-65$ years with a mean of 43 years. The disease duration ranged from three to 40 years with a mean of 10 years. All had failed conventional therapy with non-steroidal antiinflammatory drugs, including phenylbutazone and intralesional corticosteroid. All had become unemployable or were about to lose their job. In all cases the disease had continued relentlessly for at least six months. The disease activity was such that the patients were prepared to give consent to a therapy that carries potential toxicity. Approval from the Ethical Committee was granted.

Patients were randomly allocated to one of two treatment groups: azathioprine or matching placebo was given at a dose of $1 \mathrm{mg} / \mathrm{kg}$ body weight for the first four weeks followed by an increase to $2 \mathrm{mg} / \mathrm{kg}$ body weight for the next four weeks. This was followed by eight weeks on the alternative agent. The study was completed at 16 weeks. In each case phenylbutazone was withdrawn six weeks before beginning the study (in view of its potential marrow toxic effect), and another non-steroidal antiinflammatory drug was introduced. Non-steroidal anti-inflammatory agents were not changed within six weeks of the start of the study. Patients were also allowed to continue with non-anti-inflammatory analgesics. They were encouraged to taper the analgesic therapy if their clinical response allowed.

Assessment included full rheumatological evaluation and blood tests at four, eight, 12, and 16 weeks. A modified Richie index was used for the joint score. Each active joint or enthesopathic lesion was scored on a scale of $0-2$ by a single observer. All assessments were performed blindly without knowledge of treatment status. Morning stiffness was measured on a scale of $0-4 \quad(0=$ none; $1=1-30$ minutes; $2=31-60$ minutes; $3=61-120$ minutes; $4=$ over 121 minutes). A functional scale of $0-4$ was included for work both in and out of the house, bathing, and dressing. The weighted joint score (in order to avoid undue attention on joints to exclusion of other variables: joint score divided by two), plus night and day pain score $(0-4)$, together with the functional evaluation, were summated to give a global composite score (range 0-38).

\section{Results}

Six of the eight individuals completed the 16 week course. The two who dropped out included one due to drug toxicity (nausea) at one week. This individual had been receiving azathioprine. The second patient dropped out due to lack of efficacy-a patient withdrawing from the placebo trial at four
Table 1 Global composite score of eight patients with Reiter's syndrome. Pretreatment, crossover point (eight weeks), and final score are shown. Patient's preference is included

\begin{tabular}{|c|c|c|c|c|c|c|}
\hline \multirow{2}{*}{$\begin{array}{l}\text { Patient } \\
\text { No }\end{array}$} & \multirow{2}{*}{$\begin{array}{l}\text { Ist } \\
\text { Period }\end{array}$} & \multirow{2}{*}{$\begin{array}{l}\text { 2nd } \\
\text { Period }\end{array}$} & \multicolumn{2}{|c|}{ Global score* } & \multirow{2}{*}{$\frac{\text { (weeks) }}{16}$} & \multirow{2}{*}{ Patients' preference } \\
\hline & & & 0 & 8 & & \\
\hline 1 & $A^{\dagger}$ & $\mathbf{P}$ & 18 & 5 & 3 & Azathioprine \\
\hline 2 & $\mathrm{P}^{+}$ & A & 26 & 26 & 3 & Azathioprine \\
\hline 3 & A & $\mathrm{P}$ & 31 & 38 & 5 & Placebo \\
\hline 4 & A & $P$ & 25 & 3 & 35 & Azathioprine \\
\hline 5 & $\mathbf{P}$ & - & - & - & - & $\begin{array}{l}\text { Patient withdrew- } \\
\text { lack of efficacy }\end{array}$ \\
\hline 6 & A & $P$ & 28 & 10 & 14 & Azathioprine \\
\hline 7 & A & - & - & - & - & $\begin{array}{l}\text { Patient withdrew- } \\
\text { toxicity }\end{array}$ \\
\hline 8 & $\mathbf{P}$ & A & 35 & 35 & 4 & Azathioprine \\
\hline
\end{tabular}

${ }^{*}$ A composite made up of weighted joint score (i.e., empirically $\omega$ derived as onc-half joint score), morning stiffness (0-4), functional $ᄋ$ evaluation (bathing. dressing, housework, occupation: 0-4), and day and night pain scales (0-4).

$+\mathrm{A}=$ azathioprine: $\mathrm{P}=$ placebo.

Mean values for azathioprine period were 27.2 prestudy and 10.5 at the end, compared with 19.5 and 19.3 respectively for placebo. $\mathscr{O}$

weeks. At the end of 16 weeks patients were asked which period they preferred: five of the six preferred azathioprine, one placebo. For those receiving azathioprine early morning stiffness decreased from a mean of 2.9 hours to 1.9 hours at eight weeks, $\stackrel{\mathbb{Q}}{\Omega}$ while the change for those on placebo was from $2.5 \overrightarrow{\overrightarrow{0}}$ hours at the beginning to 2.7 hours at the end. The 3 joint score decreased from a mean of 19.8 to 2.7 at the end of the azathioprine period. In contrast, for those receiving placebo the mean score changed from 13.4 at the beginning of the period to 19.9 at the end. The global composite score gave mean values of 27.2 before azathioprine and 10.5 at the end, compared with 19.5 and 19.3 respectively for $ᄋ$ placebo (Table 1). Analgesic reduction was possible in four of six individuals receiving azathioprine but $\triangle$ in none of the six on placebo. The individual who $\frac{7}{0}$ failed azathioprine therapy (preferring placebo) was withdrawn from this treatment. Of the five who did N well, three needed no further immunosuppressive therapy. Patient number 4 relapsed during the $\mathrm{N}$ placebo period and needed a further 12 weeks of $\omega$ treatment, while patient 6 needed a tapering course of azathioprine for 52 weeks. The individual who을 withdrew because of lack of efficacy while on $\Phi$ placebo did later improve (an uncontrolled observa-: tion) on azathioprine $2 \mathrm{mg} / \mathrm{kg}$ tak $\triangleq n$ for eight weeks.

\section{Discussion}

There is no specific treatment for Reiter's 
syndrome. ${ }^{2}$ One leading authority stated that 'antibiotics are not recommended in the treatment of Reiter's syndrome'. The same text makes no mention of corticosteroids, gold, or penicillamine. ${ }^{2}$ It is also stated that 'azathioprine, cyclophosphamide, methotrexate, and 6-mercaptopurine all appear to be capable of suppressing the manifestations of Reiter's syndrome in doses that are tolerable, but the margin of safety in their use is limited and serious reactions, including death, may occur with any of these drugs'. ${ }^{2}$ There are only occasional reported anecdotes of cytotoxic therapy in Reiter's syndrome. $^{78}$

The decision to give an immunosuppressive drug for a disease such as Reiter's syndrome can only be taken with great difficulty since the disease itself is not lethal but the treatment may be. We had opportunity to give azathioprine in low doses to a small number of patients with Reiter's disease. We were impressed by the rapidity with which patients appeared to improve. These anecdotes led us to believe that a reduction in dosage may be made within six to eight weeks of starting therapy and that withdrawal from azathioprine may be possible within a few weeks of beginning therapy. For this reason we elected to embark on a controlled study of short term azathioprine in Reiter's syndrome. Inevitably, the numbers of patients with intractable disease would be small. Although we were aware that a double blind, crossover study was not the optimum design, it was felt that in the first instance this approach should be followed. It is self evident that studies of this type are difficult to analyse since the hoped for, long term effect of the active agent would clearly modify the placebo period when this came second. Such a phenomenon may account for patient 3 'responding' so well to the placebo period. Any washout would have to last several weeks. We therefore elected to go ahead with a straightforward crossover with no washout for this pilot study.

Despite the drawbacks inherent in such a study we have shown that azathioprine was initially helpful in five out of six individuals. The important aspect of the study was that patients made a rapid improvement within eight weeks of therapy. For four weeks of this time patients received only $1 \mathrm{mg} / \mathrm{kg}$ body weight.

It is well known that Reiter's syndrome is a difficult entity to evaluate. The relation between acute phase reactants or the erythrocyte sedimentation rate and disease activity is non-existent. ${ }^{1}$ Moreover, a single inflamed joint such as active ankle disease may prevent adequate function in spite of only limited disease. These aspects of the disorder make any attempt at a controlled drug evaluation exceptionally difficult.

One of the patients who received azathioprine for the first eight weeks and then placebo did relapse during the placebo period. At the end of the study this individual was given azathioprine once more at $1 \mathrm{mg} / \mathrm{kg}$ body weight and within six weeks was well controlled. The dose was steadily reduced, and within three months he was receiving $50 \mathrm{mg}$ on alternate days. When azathioprine was stopped there again was a relapse. Surprisingly, this exceptionally low dose maintained the patient in remission, and therapy was eventually stopped at 52 weeks. There were no drug related laboratory abnormalities during the study period.

It is important to accept these findings as 'controlled' case anecdotes rather than as a conventional double blind study. The varied course of the disease and the inability to enter sufficient patients make any clear statement inappropriate. Nevertheless, five of the six individuals who did complete the study represented a particularly encouraging early outcome, given the long term chronicity and failure to respond to conventional therapy before the study. Three of the five required no further immunosuppressive treatment. The degree to which these data can be extrapolated to the general population of patients with intractable Reiter's disease is unknown.

We acknowledge VA Research and thank Wellcome Laboratories, Research Triangle. North Carolina for generously supplying azathioprine and matching placebo.

\section{References}

1 Fox R, Calin A, Gerber R C, Gibson D. The chronicity of symptoms and disability in Reiter's syndrome: an analysis of 131 consecutive patients. Ann Intern Med 1979; 91: 190-3.

2 Sharp J T. Reiter's syndrome. In: McCarty D J, ed. Arthritis and allied conditions. Philadelphia: Lea and Febiger, 1979: 633-41.

3 Calin A. Management of Reiter's syndrome. Ann Rheum Dis 1979; 38 (suppl): 96-7.

4 Calin A. Reiter's syndrome. In: Kelley W N, Harris E D, Ruddy S, Sledge C B, eds. Textbook of rheumatology. Philadelphia: Saunders, 1981; II: 1033-46.

5 Mowat A G, Chalmers T M, Alexander W R M, Duthie J J R. Case of Reiter's disease treated with Lincomycin hydrochloride. Br Med J 1967; i: 478.

6 Black R L, O'Brien W M, Van Scott E J, et al. Methotrexate therapy in psoriatic arthritis. JAMA 1964; 189: 743-7.

7 Farber G A, Forshner J G, O'Quinn S E. Reiter's syndrome, treatment with methotrexate. JAMA 1967; 200: 171-3.

8 Mullins J F, Maberry J D, Stone O J. Reiter's syndrome treated with folic acid antagonists. Arch Dermatol 1966; 94: 335-9. 